\title{
High density lipoprotein apolipoprotein Al kinetics in NIDDM: a stable isotope study
}

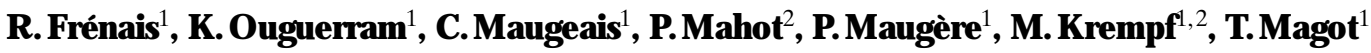 \\ ${ }^{1}$ Centre de Recherche en Nutrition Humaine, Hôpital G. \& R. Laënnec, Nantes, France \\ ${ }^{2}$ Clinique d'Endocrinologie, Maladies Métaboliques et Nutrition, Hôtel Dieu, Nantes, France
}

Summary High density lipoprotein (HDL) kinetics were studied by infusing $\left[5,5,5-{ }^{2} \mathrm{H}_{3}\right]$-leucine in five subjects with normal glucose tolerance and eight patients with non-insulin-dependent diabetes mellitus $(\mathrm{NIDDM})$ with poor metabolic control $\left(\mathrm{HbA}_{1 \mathrm{c}}=\right.$ $8.16 \pm 1.93 \%)($ mean \pm SD). HDL were modelled as a single compartment since no kinetic differences were observed between HDL2 and HDL3 subclasses. Plasma apolipoprotein AI (apo AI) concentration was significantly lower in NIDDM patients $\left(96.1 \pm 12.1\right.$ vs $\left.124.4 \pm 13.1 \mathrm{mg} \cdot \mathrm{dl}^{-1}, \mathrm{p}<0.01\right)$. HDL composition was altered in NIDDM, as an increase in HDL-triglyceride and a decrease in HDL-cholesterol, negatively correlated $(r=-0.780, p<0.01)$. The mean fractional catabolic rate (FCR) of apo AIHDL was significantly higher $(0.39 \pm 0.16$ vs $0.21 \pm$ $\left.0.06 \mathrm{~d}^{-1}, \mathrm{p}<0.05\right)$ while the apo AI-HDL absolute production rate was not significantly greater $\left(13.6 \pm 5.1 \mathrm{vs} 12.0 \pm 4.2 \mathrm{mg} \cdot \mathrm{kg}^{-1} \cdot \mathrm{d}^{-1}\right)$ in diabetic patients compared to normal subjects. There were significant correlations between apo AI-HDL FCR and plasma apo AI concentration $(r=-0.580, p<0.05)$, plasma triglycerides $(r=0.839, p<0.001)$ or HDLtriglyceride levels $(r=0.597, p<0.05)$. No correlation was observed between apo AI-HDL FCR and $\mathrm{HbA}_{1 \mathrm{c}}$ or HDL-cholesterol level. These data support the view that the decrease in plasma apo AI level in patients with NIDDM is due to an increase of apo AIHDL FCR, which may itself be related to changes in HDL composition. [Diabetologia (1997) 40: 578-583]

Keywords Non-insulin-dependent diabetes mellitus, HDL-cholesterol, apolipoprotein AI, stable isotope, fractional catabolic rate, kinetic analysis.
Atherosclerosis is the major cause of morbidity and mortality among non-insulin-dependent diabetic (NIDDM) patients. High density lipoprotein (HDL)-cholesterol level is reduced in NIDDM patients $[1,2]$ and this appears directly correlated with an increased risk of coronary heart disease [3, 4]. Moreover, plasma apolipoprotein AI (apo AI) concentration is reported to correlate inversely with the

Received: 15 October 1996 and in revised form: 17 January 1997

Corresponding author: Dr. M.Krempf, Clinique d'Endocrinologie, Hôtel Dieu, F-44035 Nantes Cedex 01, France A bbreviations: HDL, High density lipoproteins; NIDDM, noninsulin-dependent diabetes mellitus; Apo AI, apolipoprotein AI; FCR, fractional catabolic rate; FPR, fractional production rate; CETP, cholesteryl ester transfer protein. atherosclerosis risk [5]. However, it is still not known whether the concentration of apo AI is determined predominantly by a decrease in synthetic rate or by an increase in catabolic rate in NIDDM. Endogenous labelling of apo AI using stable isotopes is an established method in kinetic studies for studying in vivo metabolism of HDL [6]. But, only one study reported on an in vitro labelling of HDL with ${ }^{3} \mathrm{H}$-apo $\mathrm{AI}$ in NIDDM patients [7], showing that the decrease in plasma HDL-cholesterol and apo AI levels was related to an increase in the catabolic rate of apo AIHDL. However, in primarily unpublished works, conflicting results were reported by the same authors also using a radioactive method [8], and this might suggest that in vitro labelling of lipoprotein could affect kinetic data per se [9]. Thus, the present study assessed the kinetic parameters of apo AI-HDL using an endogenous labelling with stable isotopes, as well 
as their correlations with several other metabolic variables, such as plasma apo AI or lipid concentrations, that are usually altered in NIDDM.

\section{Subjects, materials and methods}

Subjects. A kinetic study of apo AI metabolism was performed in five healthy, normolipidaemic subjects with normal glucose tolerance and eight NIDDM patients. All control subjects were in good general health and none was taking any medication that could affect carbohydrate or lipid metabolism. Insulin treatment was an exclusion criteria for our NIDDM population. Relevant clinical characteristics of the two groups are shown in Table 1. Study subjects were instructed by a dietician to eat a weight-maintenance diet composed of $45 \%$ of the usual daily caloric intake as carbohydrate, $35 \%$ as fat and $20 \%$ as protein, for at least 1 week prior to the study. The experimental protocol was approved by the ethics committee of the University Hospital, and informed consent was obtained before the study was started.

Experimental protocol. The endogenous labelling of apo AI was carried out by administration of L-[5,5,5- $\left.{ }^{2} \mathrm{H}_{3}\right]$-leucine (99.8 Atom \%; Mass Trace, Woburn, Mass., USA), dissolved in a $0.9 \% \mathrm{NaCl}$ solution and tested for pyrogenicity and sterility before the study. All subjects fasted overnight for $12 \mathrm{~h}$ prior to the study, and remained fasting during the entire procedure. Each subject received intravenously a prime of $10 \mu \mathrm{mol} \cdot \mathrm{kg}^{-1}$ of tracer, immediately followed by a constant tracer infusion $\left(10 \mu \mathrm{mol} \cdot \mathrm{kg}^{-1} \cdot \mathrm{h}^{-1}\right)$ for $14 \mathrm{~h}$. Venous blood samples were drawn into EDTA tubes (Venoject, Paris, France) at baseline, every $15 \mathrm{~min}$ during the first hour, every $30 \mathrm{~min}$ during the next $2 \mathrm{~h}$, and then hourly until the end of the study. Plasma was immediately separated by centrifugation for $30 \mathrm{~min}$ at $4{ }^{\circ} \mathrm{C}$; sodium azide, an inhibitor of bacterial growth, and Pefabloc SC (Interchim, Montluçon, France), a protease inhibitor, were added to blood samples at a final concentration of 1.5 and $0.5 \mathrm{mmol} / 1$, respectively.

\section{A nalytical procedures}

Measurement, isolation and preparation of apolipoproteins. VLDL (density (d) $<1.006 \mathrm{~g} / \mathrm{ml})$, HDL2 $(1.063<\mathrm{d}<1.125 \mathrm{~g}$ / $\mathrm{ml})$ and HDL3 $(1.125<\mathrm{d}<1.210 \mathrm{~g} / \mathrm{ml})$ were isolated from $3 \mathrm{ml}$ of plasma by a density gradient ultracentrifugation method [10] using a swinging bucket rotor at $40000 \mathrm{rev} . / \mathrm{min}^{-1}$ for $24 \mathrm{~h}$ at $10^{\circ} \mathrm{C}$ (Centrikon T 2060, Kontron Instruments, Kontron: Zürich, Switzerland). Plasma and HDL cholesterol and triglyceride levels were measured using commercially available enzymatic kits (Boehringer Mannheim GmbH, Mannheim, Germany) at three different sampling times : 3, 8 and $12 \mathrm{~h}$. Apo AI concentration was measured in plasma and HDL fractions by immunonephelemetry (Behring, Rueil Malmaison, France) at the same sampling times.

Apo AI-HDL and apo B100-VLDL were concentrated [11] and isolated from other apolipoproteins by sodium dodecylsulfate polyacrylamide gel electrophoresis (SDS-PAGE) using a 4-5-10\% discontinuous gradient. Apolipoproteins were identified by comparing migration distances with known molecular weight standards (Cross-linked phosphorylase b markers, Sigma, St. Louis, Mo., USA, and electrophoresis calibration kit, Pharmacia LKB, Biotechnology Inc., Piscataway, N. J., USA). Apolipoprotein bands were excised from polyacrylamide gels
Table 1. Selected clinical and biological characteristics of study subjects

\begin{tabular}{lll}
\hline & $\begin{array}{l}\text { Control subjects } \\
(\mathrm{n}=5)\end{array}$ & $\begin{array}{l}\text { NIDDM patients } \\
(\mathrm{n}=8)\end{array}$ \\
\hline Age $($ years $)$ & $25 \pm 3$ & $46 \pm 12^{\mathrm{a}}$ \\
Sex $($ male $/$ female $)$ & $5 / 0$ & $1 / 7$ \\
BMI $\left(\mathrm{kg} \cdot \mathrm{m}^{-2}\right)$ & $21.2 \pm 1.0$ & $29.5 \pm 3.2^{\mathrm{b}}$ \\
Fasting blood glucose & & \\
$\left(\mathrm{mmol}^{-1}\right)$ & $4.2 \pm 0.6$ & $12.2 \pm 3.3^{\mathrm{b}}$ \\
$\mathrm{HbA}_{1 \mathrm{c}}(\%)$ & $4-6.5$ & $8.16 \pm 1.93$ \\
Insulin $\left(\mathrm{pmol} \cdot \mathrm{l}^{-1}\right)$ & $61.4 \pm 9.7$ & $122.8 \pm 29.0^{\mathrm{b}}$ \\
\hline
\end{tabular}

Values are means $\pm \mathrm{SD}$

${ }^{\mathrm{a}} \mathrm{p}<0.01 ;{ }^{\mathrm{b}} \mathrm{p}<0.001$

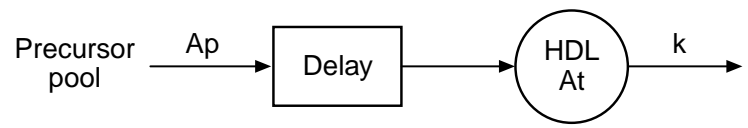

Fig. 1. One-compartment model for kinetic analysis of apo AIHDL metabolism

and dried in vacuum for 1 to $2 \mathrm{~h}$ (RC 10-10 Jouan, Saint Herblain, France). The dessicated gel slices were hydrolysed with $1 \mathrm{ml}$ of $4 \mathrm{~N} \mathrm{HCi} \mathrm{(Sigma,} \mathrm{St} \mathrm{Quentin} \mathrm{Fallavier,} \mathrm{France)} \mathrm{at}$ $110^{\circ} \mathrm{C}$ for $24 \mathrm{~h}$.

D etermination of tracer-to-tracee ratios. Hydrolysates were evaporated to dryness and the amino acids purified by cation exchange chromatography using a Temex $50 \mathrm{~W}-\mathrm{X} 8$ resin (Biorad: Hercules, Calif., USA). Amino acids and plasma leucine were esterified with propanol/acetyl chloride, and derivatized using heptafluorobutyric anhydride (Fluka Chemie AG, Buchs, Switzerland) prior to analysis. Chromatographic separations were carried out on a $30 \mathrm{~m} \times 0.252 \mathrm{~cm}$ internal diameter DB-5 capillary column ( $\&$ \& W Scientific, Rancho Cordova, Calif., USA). The column temperature program was as follows: initial temperature was held at $80^{\circ} \mathrm{C}$ for $1 \mathrm{~min}$, then increased at $10^{\circ} \mathrm{C} \cdot \mathrm{min}^{-1}$ to a final temperature of $180^{\circ} \mathrm{C}$. Electron-impact gas chromatography-mass spectrometry was performed on a 5891 A gas chromatograph connected with a 5971 A quadrupole mass spectrometer (Hewlett Packard, Palo Alto, Calif., USA). The isotopic ratio was determined by selected ion-monitoring at $\mathrm{m} / \mathrm{z}$ of 282 and 285 . Calculations of apo AI kinetic parameters were based on the tracer-to-tracee mass ratio [12].

Modelling. Kinetic analysis of tracer-to-tracee ratios was achieved using computer software for simulation, analysis and modelling (SAAM II v 1.0.1, Resource Facility for Kinetic Analysis, Department of Bioengineering, SAAM Institute, Seattle, Wash., USA). The model used (Fig.1) was a one-compartment model. The fractional production rate (FPR), i.e. the proportion of apo AI entering the pool per unit time $\left(\mathrm{d}^{-1}\right)$, and the absolute production rate, i. e. the amount of apo AI entering the pool per unit time $\left(\mathrm{mg} \cdot \mathrm{kg}^{-1} \cdot \mathrm{d}^{-1}\right)$ were estimated. Absolute production rate is the product of FPR multiplied by apo AI mass in HDL. As precursor pool estimation for apo AI, it was assumed that the VLDL-apo B100 tracer-to-tracee ratio at the end of the primed constant infusion corresponded to the tracer-to-tracee ratio of the leucine precursor pool. This estimation is made upon the assumption that apo B100 and 
the majority of apo AI are synthesized by the liver [6]. This pool was considered to be constant owing to the steady-state observed on plasma leucine tracer-to-tracee ratio (not shown). Under these conditions, FPR equals FCR. VLDL apo B100 and HDL apo AI data were kinetically analysed using a monoexponential function [6]: $\mathrm{A}(\mathrm{t})=\mathrm{Ap}[1-\exp (-\mathrm{k}(\mathrm{t}-\mathrm{d}))]$, where $\mathrm{A}(\mathrm{t})$ is the tracer-to-tracee ratio at time $\mathrm{t}(\mathrm{h})$, Ap, the tracerto-tracee ratio at the plateau of the VLDL apo B100 curve (representing the tracer-to-tracee ratio of the precursor pool), $\mathrm{d}(\mathrm{h})$, the delay between the beginning of the experiment and the appearance of tracer in the apolipoprotein, and $\mathrm{k}$ the FCR of the apolipoprotein.

\section{Statistical analysis}

Data are reported as mean \pm SD unless otherwise specified. The Student's unpaired t-test (two tailed p value) was used to determine significant differences between groups. Linear regression and correlation analyses were performed using the Instat statistical Software package (GraphPad, San Diego, Calif., USA).

\section{Results}

A polipoprotein and lipid concentrations. Individual data for plasma and HDL composition are presented in Table 2. As no significant variation was observed between measurements made at three different infusion times (data not shown), it was considered that all volunteers (control and diabetic subjects) were in steady-state throughout the study. The apo AI pool size $\left(\mathrm{mg} \cdot \mathrm{kg}^{-1}\right)$ was therefore calculated by multiplying the mean plasma apo AI concentration by 0.045 and $0.037\left(1 \cdot \mathrm{kg}^{-1}\right)$, assuming a plasma volume of respectively $4.5 \%$ of body weight for control subjects and $3.7 \%$ for diabetic patients [13]. The plasma apo AI concentration was taken to be the HDL apo AI concentration, under the assumption that over $90 \%$ of plasma apo AI resides in HDL fraction [14].

Diabetic patients showed characteristic higher fasting plasma glucose and insulin concentrations (Table 1). As expected, a higher glycosylated haemoglobin level $(8.16 \pm 1.93 \%)$ was found in diabetic patients (normal range for healthy subjects: 4-6.5\%). Six diabetic patients were hypertriglyceridaemic (plasma triglycerides $>1.71 \mathrm{mmol} \cdot \mathrm{l}^{-1}$ ). Furthermore, compared to control subjects, patients with NIDDM had higher plasma cholesterol concentration, but lower HDL-cholesterol level $(p<0.001)$. Plasma apo AI concentration was significantly lower $(p<0.01)$ in diabetic patients (Table 2).

Kinetic data. Enrichment in plasma-free leucine reached a plateau value after $30 \mathrm{~min}$ and remained stable through to the end of the study (not shown). The tracer-to-tracee ratio curves in VLDL and HDL are shown in Figures 2 and 3, respectively, for both control and diabetic subjects (mean \pm SEM). A plateau (which represented about $70 \%$ of the plasma
Table 2. Plasma and HDL composition $\left(\mathrm{mmol} \cdot \mathrm{l}^{-1}\right)$ of study subjects

\begin{tabular}{lcc}
\hline & $\begin{array}{l}\text { Control } \\
\text { subjects }\end{array}$ & $\begin{array}{l}\text { NIDDM } \\
\text { patients }\end{array}$ \\
\hline Plasma apo AI (mg/dl) & $124.4 \pm 13.1$ & $96.1 \pm 12.1^{\mathrm{a}}$ \\
Plasma cholesterol & $3.95 \pm 0.84$ & $3.60 \pm 0.84$ \\
Plasma triglyceride & $0.92 \pm 0.23$ & $2.35 \pm 0.99^{\mathrm{a}}$ \\
HDL-cholesterol & $1.40 \pm 0.15$ & $0.93 \pm 0.19^{\mathrm{b}}$ \\
HDL-triglyceride & $0.05 \pm 0.02$ & $0.17 \pm 0.07^{\mathrm{a}}$ \\
Apo AI/HDL-cholesterol ratio & $89.2 \pm 6.3$ & $107.5 \pm 32.3$ \\
\hline
\end{tabular}

Values are means \pm SD

${ }^{\mathrm{a}} \mathrm{p}<0.01 ;{ }^{\mathrm{b}} \mathrm{p}<0.001$

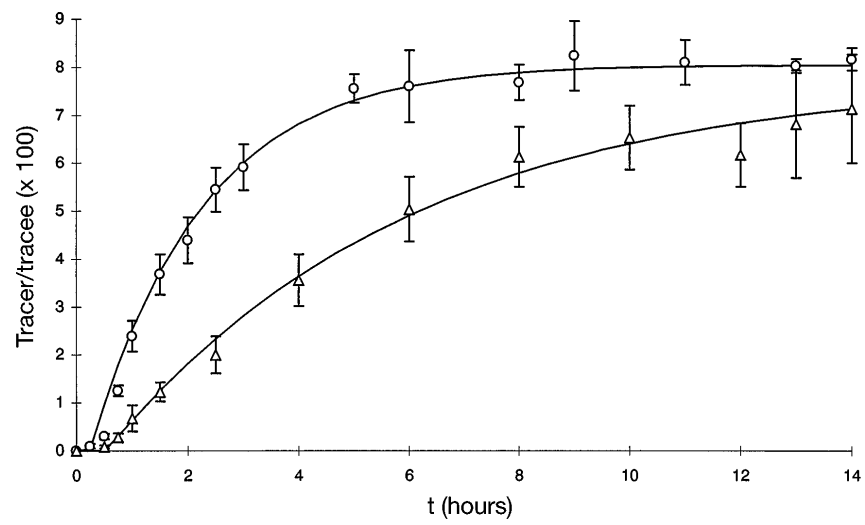

Fig. 2. Experimental values of the tracer-to-tracee ratio for apo B100-VLDL in representative control subject $(O)$ and NIDDDM patient $(\triangle)$. Fits (lines) were calculated using monocompartmental analysis during a primed constant infusion of $\left[{ }^{2} \mathrm{H}_{3}\right]$-leucine. Data are shown as mean \pm SEM

leucine plateau) of tracer-to-tracee ratio was observed for VLDL-apo B100 but not for apo AI-HDL (only $15 \%$ of the latter at time $14 \mathrm{~h}$ ), meaning a slow synthetic rate for this apolipoprotein. Experimental data in HDL2 and HDL3 were similar (Fig.4) in both control and NIDDM population (mean \pm SEM). Kinetic parameters of apo AI are shown in Table 3. The FCR of apo AI-HDL was significantly increased $(86 \%, p<0.05)$, and apo AI pool size was significantly lower in diabetic patients, compared to control subjects $(p<0.001)$. Despite a $36 \%$ reduction in apo AI pool size in NIDDM, the absolute production rate was higher $(14 \%)$, but not significantly $(p=0.550)$, compared to control subjects.

Correlations. No correlation was found between the FCR of apo AI and plasma or HDL composition for the control population. A significant positive correlation $(r=0.736, p<0.05)$ was established between FCR of apo AI and plasma triglyceride level in the NIDDM patients, but FCR of apo AI was not correlated with $\mathrm{HbA}_{1 \mathrm{c}}$. When we pooled both study groups, significant correlations (Table 4) were observed between FCR of apo AI and plasma apo AI 


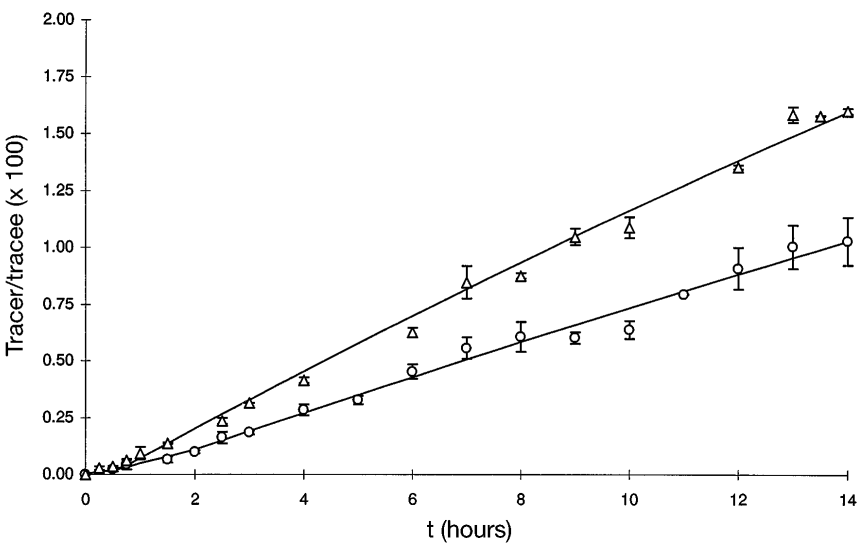

Fig. 3. Experimental values of the tracer-to-tracee ratio for apo AI-HDL in representative control subject $(O)$ and NIDDDM patient $(\triangle)$. Fits (lines) were calculated using monocompartmental analysis during a primed constant infusion of $\left[{ }^{2} \mathrm{H}_{3}\right]$-leucine. Data are shown as mean \pm SEM

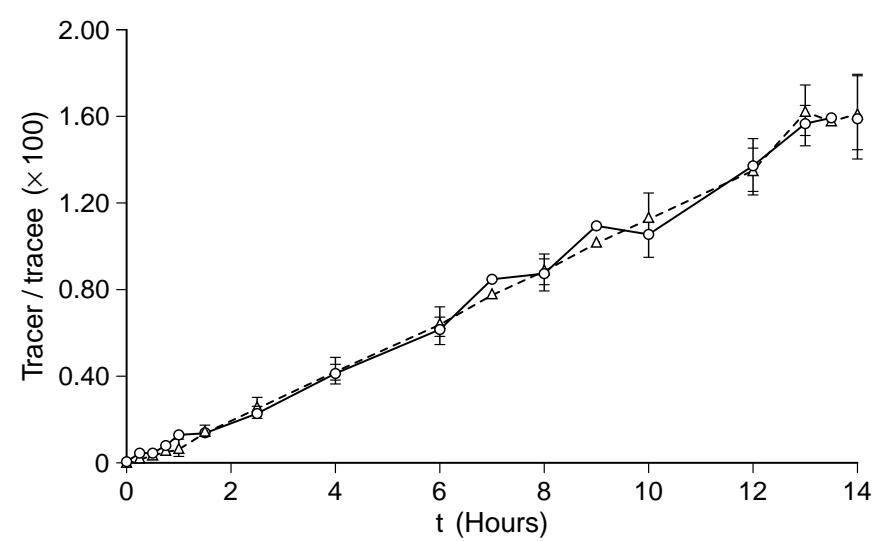

Fig. 4. Experimental values of the tracer-to-tracee ratio for apo AI-HDL2 $(O)$ and apo AI-HDL3 $(\triangle)$ in a representative control subject, during a primed constant infusion of $\left[{ }^{2} \mathrm{H}_{3}\right]$-leucine. Data are shown as mean \pm SEM

$(r=-0.580, p<0.05)$, plasma triglycerides $(r=0.839$, $p<0.001)$ and HDL-triglycerides $\quad(r=0.597$, $p<0.05$ ). Regardless of the population considered, we did not find any correlation between the FCR of apo AI and plasma or HDL-cholesterol levels, or apo AI-to-HDL-cholesterol ratio. No correlation was found between absolute production rate of apo $\mathrm{AI}$ and plasma variables or HDL composition. There was a significant negative correlation between HDLcholesterol and HDL-triglycerides $(r=-0.780$, $\mathrm{p}<0.01)$.

\section{Discussion}

The aim of this study was to determine the kinetic variations in apo AI-HDL metabolism in NIDDM. A primed constant infusion of deuterated leucine was administered to five healthy subjects and eight
Table 3. Kinetic parameters of apo AI-HDL in study subjects

\begin{tabular}{lll}
\hline & $\begin{array}{l}\text { Control } \\
\text { subjects }\end{array}$ & $\begin{array}{l}\text { NIDDM } \\
\text { patients }\end{array}$ \\
\hline Apo AI FCR $\left(\mathrm{d}^{-1}\right)$ & $0.21 \pm 0.06$ & $0.39 \pm 0.16^{\mathrm{a}}$ \\
Apo AI pool size $\left(\mathrm{mg} \cdot \mathrm{kg}^{-1}\right)$ & $56.0 \pm 5.9$ & $35.6 \pm 4.5^{\mathrm{b}}$ \\
Apo AI APR $\left(\mathrm{mg} \cdot \mathrm{kg}^{-1} \cdot \mathrm{d}^{-1}\right)$ & $12.0 \pm 4.2$ & $13.6 \pm 5.1$ \\
\hline
\end{tabular}

Values are means $\pm \mathrm{SD}$

${ }^{\mathrm{a}} \mathrm{p}<0.05 ;{ }^{\mathrm{b}} \mathrm{p}<0.0001$

Table 4. Correlation coefficient analysis ( $r$ values) in both control and NIDDM populations

\begin{tabular}{lcc}
\hline & FCR apo AI & APR apo AI \\
\hline Plasma apo AI & $-0.580^{\mathrm{a}}$ & -0.078 \\
Plasma cholesterol & 0.103 & 0.207 \\
Plasma triglyceride & $0.839^{\mathrm{b}}$ & 0.549 \\
HDL-cholesterol & -0.473 & -0.133 \\
HDL-triglyceride & $0.597^{\mathrm{a}}$ & 0.241 \\
Apo AI/HDL-cholesterol ratio & 0.058 & 0.073 \\
\hline${ }^{\mathrm{a}} \mathrm{p}<0.05 ;{ }^{\mathrm{b}} \mathrm{p}<0.001$ & &
\end{tabular}

NIDDM patients who fasted the night before and during the 14-h experiment. Endogenous labelling of apolipoproteins by infusion of an amino acid labelled with a stable isotope is now widely used for physiological studies and exploration of dyslipoproteinaemia [9]. However, to our knowledge, this study is the first to report an endogenous labelling of apo AI-HDL using stable isotopes in NIDDM patients.

Plasma apo AI and HDL-cholesterol concentrations were significantly lower in NIDDM patients than in control subjects, whereas plasma and HDLtriglyceride levels were higher. Furthermore, the FCR of apo AI-HDL was greater in patients with NIDDM, but apo AI-HDL production rate was not significantly altered. This increased FCR was negatively correlated with plasma apo AI concentration and positively correlated with plasma and HDL-triglyceride levels. No correlation was found between $\mathrm{HbA}_{1 \mathrm{c}}$ and plasma lipid parameters. In fact, $\mathrm{HbA}_{1 \mathrm{c}}$ reflects the blood glucose prevailing over a 2 month period, whereas triglyceride level can change in a very short time. This faster variation may explain the lack of correlation.

The tracer-to-tracee ratios in HDL2 and HDL3 were similar, indicating a fast rate of interconversion between these subclasses of lipoproteins [15]. Thus, under our study conditions, kinetic heterogeneity was not required, and HDL were modelled as a single compartment [16]. Our two study groups were not well-matched for BMI, age or gender, but individual data obtained from several studies indicated that neither sex [14], nor BMI (range 23.0-31.7 $\mathrm{kg} \cdot \mathrm{m}^{-2}$ ) [1719] or age (21.3-47.1 years) [20] were major factors determining apo AI-HDL turnover rate.

Our kinetic data are in agreement with a similar study [7] using tritiated apo AI-HDL to measure the 
HDL turnover in NIDDM patients, even though kinetic parameters calculated using radioisotopes were higher. Golay et al. [7] indicated that FCRs of apo AI were 0.39 and $0.63 \mathrm{~d}^{-1}$ for control and diabetic subjects, respectively, compared to 0.21 and $0.39 \mathrm{~d}^{-1}$ in our study. Yet these kinetic parameters were calculated over two different periods: blood samples were collected over 14 days in the study of Golay et al. [7], instead of a 14-h period in our own protocol. This may explain the difference of apo AI turnover rate. Ikewaki et al. [21] showed in healthy subjects that endogenous labelling of apo AII with stable isotopes was a good alternative to the exogenous radiotracer labelling method for the determination of apo AII turnover. However, under their experimental conditions, apo AII residence times determined after exogenous labelling were significantly shorter compared to those obtained after an endogenous labelling protocol. This suggested that the true apo AII turnover may be slower than that calculated with a radiotracer study, and indicated the problem of hypothetical apolipoprotein modifications during purification and radioiodination. Thus, even if apo AI and AII metabolisms are not quite identical [22], this study supports the validity of our results compared to those of Golay et al. [7].

In theory, the low plasma apo AI level observed in patients with NIDDM could be due either to a decrease in the production rate or an increase in the catabolic rate of this apolipoprotein. Considering that the FCR of apo AI-HDL was significantly greater in diabetic patients than in control subjects, whereas absolute production rate was not significantly changed, our data suggest that the production rate was not affected, while the increase in catabolic rate caused the decrease in apo AI level. This was supported by the negative correlation observed between plasma apo AI concentration and FCR of apo AI. As recently reported [23], metabolic studies of apo AI in healthy subjects have established that variations in apo AI levels are primarily due to changes in the rate of apo AI catabolism, rather than in production rate $[14,20,24]$. Therefore, the FCR of apo AI may determine plasma apo AI level in NIDDM patients. Conversely, in an animal model, reduced apo AI catabolism was shown to account for increased plasma apo AI levels [25].

Alterations in plasma and HDL lipid distribution in NIDDM patients compared to control subjects help explain variations in HDL metabolism. Decreased HDL-cholesterol and increased HDL-triglyceride levels were commonly observed in diabetic patients $[1,2]$, as in this present study. The negative correlation between HDL-cholesterol and HDL-triglycerides we report suggests an alteration in the composition of HDL in NIDDM. As suggested by Biesbroeck et al. [1], it could be proposed that elevated plasma triglyceride levels led to a decrease in
HDL-cholesterol levels, through substitution for esterified cholesterol with triglyceride in the lipid core.

Moreover, positive correlations were found between FCR of apo AI and plasma or HDL-triglyceride concentrations. As most of our diabetic patients were hypertriglyceridaemic, we believe that the increase in apo AI-HDL FCR in patients with NIDDM was related to their high plasma triglyceride level, and this might be directly related to plasma apo AI level [14]. Brinton et al. [17] reported the turnover of radioiodinated HDL apolipoproteins in subjects with low HDL-cholesterol and normal or high plasma triglyceride and compared them to control subjects with both normal HDL-cholesterol and plasma triglyceride levels. Although this study did not deal with NIDDM patients, these populations were similar to ours, regarding the cholesterol and triglyceride levels. They showed an increased apo AI FCR for the populations with a low HDL-cholesterol, and concluded that high FCR characterized low HDL-cholesterol, regardless of plasma triglyceride level. Moreover, as in our present study, absolute production rate of apo AI did not significantly differ between the two groups. Thus, it was hypothesized that elevated HDL apo AI FCR is the major metabolic mechanism of low HDL-cholesterol levels in both normal-triglyceride and hypertriglyceridaemic subjects, suggesting that hypertriglyceridaemia is not a unique cause of the elevated FCR. Other factors, such as cholesteryl ester transfer protein (CETP) or hepatic lipase activities, could combine with this factor to account for the increased FCR in patients with low HDL-cholesterol, such as NIDDM subjects. Ahnadi et al. [26] measured the in vitro unidirectional transfer of esterified cholesterol from HDL to VLDL and LDL in diabetic subjects. HDL transported less esterified cholesterol, and this was related to a higher triglyceride content. In HDL lipid core, cholesterol was replaced by triglycerides, promoting atherosclerosis. The triglyceride: cholesteryl ester exchange, mediated by the CETP, is a cause of remodelling of HDL into smaller particles [27]. HDL in NIDDM are small sized and have low cholesterol content [28]. Considering that human cholesterol levels are determined by apo AI FCR [17], which correlates inversely with HDL particle size [29], apo AI catabolism is enhanced in the diabetic population. So, CETP enzymatic activity measurement and HDL size calculation could be of outstanding interest in our two study populations.

Furthermore, Horowitz et al. [30] proposed a mechanism to explain the relationship between HDL composition and apo AI catabolism rate. In subjects with increased CETP-mediated exchange of core lipids, like NIDDM patients [31], HDL-cholesteryl ester concentration is low and HDL-triglyceride level is higher. Since apo AI is weakly bound to cholesteryl ester-depleted particles, there is more apo AI in an easily dissociable pool that can be 
readily catabolized. So apo AI FCR is faster, and thus apo AI level decreased. However, evidence that cholesteryl ester-triglycerides exchange is greater in NIDDM is not clearly established [26, 32].

In conclusion, results of this present study provide further understanding on some of the metabolic disturbances in NIDDM patients. We showed that the decrease in plasma apo AI concentration is in part due to an increase of FCR of apo AI-HDL in diabetic subjects. Because other parameters that affect HDL lipid composition and size (such as CETP activity) could modulate apo AI-HDL kinetics in NIDDM patients, further studies regarding HDL composition and metabolism are clearly warranted. Finally, the stable isotope endogenous labelling method used in the current work may be a fruitful approach for HDL metabolic studies in NIDDM.

A cknowledgements. We thank Ms. I. Grit and C. Levalegant for their excellent technical assistance; D. Darmaun and A.C.Heatherington for their reviews and advice. This work was supported by a grant from the University of Nantes, Pierre Fabre Santé and Rhône-Poulenc Rorer Companies.

\section{References}

1. Biesbroeck RC, Albers JJ, Wahl PW, Weinberg CR, Bassett ML, Bierman EL (1982) Abnormal composition of high density lipoproteins in noninsulin-dependent diabetics. Diabetes 31: 126-131

2. Briones ER, Mao SJT, Palumbo PJ, O'Fallon WM, Chenoweth W, Kottke BA (1984) Analysis of plasma lipids and apolipoproteins in insulin-dependent and noninsulin-dependent diabetics. Metabolism 33: 42-49

3. Forte TM, McCall MR (1994) The role of apolipoprotein AI-containing lipoproteins in atherosclerosis. Curr Opin Lipidol 5: 354364

4. Gordon T, Castelli WP, Hjortland MC, Kannel WB, Dawber TR (1977) High density lipoprotein as a protective factor against coronary heart disease. Am J Med 62: 707-714

5. Avogaro PG, Bittolo Bon G, Cazzolato G, Quinci GB (1979) Are apolipoproteins better discriminators than lipids for atherosclerosis? Lancet i: 901-903

6. Ikewaki K, Rader DJ, Schaefer JR, Fairwell T, Zech LA, Brewer HBJ (1993) Evaluation of apo AI kinetics in human using simultaneous endogenous stable isotope and exogenous radiotracers methods. J Lipid Res 34: 2207-2215

7. Golay A, Zech L, Shi MZ, Chiou YAM, Reaven GM, Chen YDI (1987) High density lipoprotein (HDL) metabolism in noninsulin-dependent diabetes mellitus: measurement of DHL turnover using tritiated HDL. J Clin Endocrinol Metab 65: 512-518

8. Golay A, Zech L, Shi MZ, Chiou YAM, Chen YDI (1985) High density lipoprotein (HDL) turnover in noninsulin-dependent diabetes mellitus (NIDDM). Diabetes 34: 81 A (Abstract)

9. Schaefer JR, Rader DJ, Brewer HBJ (1992) Investigation of lipoprotein kinetics using endogenous labeling with stable isotopes. Curr Opin Lipidol 3: 227-232

10. Chapman MJ, Goldstein S, Lagrange D, Laplaud PM (1981) A density gradient ultracentrifugal procerdure for the isolation of the major lipoprotein classes from human serum. J Lipid Res 22: 339-358

11. Mindham MA, Mayes PA (1992) A simple and rapid method for preparation of apolipoproteins for electrophoresis. J Lipid Res 33: $1084-1088$

12. Foster DM, Barrett PHR, Toffolo G, Beltz WF, Cobelli C (1993) Estimating the fractional synthetic rate of plasma apolipoproteins and lipids from stable isotope data. J Lipid Res 34: 2193-2205
13. Dagher FJ, Lyons JH, Finlayson DC, Shamsai J, Moore FD (1965) Blood volume measurement: a critical study. Prediction of normal values, controlled measurement of sequential changes, choice of a bedside method. Advanc Surg 1: 69-109

14. Schaefer EJ, Zech LA, Jenkins LL (1982) Human apolipoprotein AI and AII metabolism. J Lipid Res 23: 850-862

15. Schaefer EJ, Foster DM, Jenkins LL, Lindgren FT, Berman M, Levy RI, Brewer HBJ (1979) The composition and metabolism of high density lipoprotein subfractions. Lipids 14: 511-522

16. Walsh BW, Li H, Sacks FM (1994) Effects of postmenopausal hormone replacement with oral and transdermal estrogen on high density lipoprotein metabolism. J Lipid Res 35: 2083-2093

17. Brinton EA, Eisenberg S, Breslow JL (1991) Increased apo AI and apo AII fractional catabolic rate in patients with low high density lipoprotein-cholesterol levels with or without hypertriglyceridemia. J Clin Invest 87: 536-544

18. Taskinen MR, Kahri J, Koivisto V, Shepherd J, Packard CJ (1992) Metabolism of HDL apolipoprotein AI and AII in type 1 (insulin-dependent) diabetes mellitus. Diabetologia 35: 347-356

19. Rader DJ, Castro G, Zech LA, Fruchart JC, Brewer HBJ (1991) In vivo metabolism of apolipoprotein $\mathrm{AI}$ on high density lipoprotein particles Lp AI and Lp AI : AII. J Lipid Res 32: 1849-1859

20. Brinton EA, Eisenberg S, Breslow JL (1989) Elevated high density lipoprotein cholesterol levels correlate with decreased apolipoprotein AI and AII fractional catabolic rate in women. J Clin Invest 84: $262-269$

21. Ikewaki K, Zech LA, Brewer HBJ, Rader DJ (1996) Apo AII kinetics in human using endogenous labeling with stable isotopes: slower turnover of apo AII compared with the exogenous radiotracer method. J Lipid Res 37: 399-407

22. Zech LA, Schaefer EJ, Bronzert TJ, Aamodt RL, Brewer HBJ (1983) Metabolism of human apolipoprotein AI and AII: compartmental models. J Lipid Res 24: 60-71

23. Rader DJ, Ikewaki K (1996) Unravelling high density lipoproteinapolipoprotein metabolism in human mutants and animals models. Curr Opin Lipidol 7: 117-123

24. Ikewaki K, Zech LA, Kindt M, Brewer HBJ, Rader DJ (1995) Apolipoprotein AII production rate is a major factor regulating the distribution of apolipoprotein AI among HDL subclasses Lp $\mathrm{AI}$ and Lp AI : AII in normolipidemic humans. Arterioscler Thromb Vasc Biol 15: 306-312

25. Kaysen GA, Hoye E, Jones HJ (1995) Apolipoprotein AI levels are increased in part as a consequence of reduced catabolism in nephrotic rats. Am J Physiol 268: F532-F540

26. Ahnadi CE, Masmoudi T, Berthezene F, Ponsin G (1993) Decreased ability of high density lipoproteins to transfer cholesterol esters in noninsulin-dependent diabetes mellitus. Eur J Clin Invest 23: 191-196

27. Hayek T, Azrolan N, Verdery RB, Walsh A, Chajek-Shaul T, Agellon LB, Tall AR, Breslow JL (1993) Hypertriglyceridemia and cholesteryl ester transfer protein interact to dramatically alter high density lipoprotein levels, particle sizes, and metabolism. J Clin Invest 92: 1143-1152

28. Syvänne M, Ahola M, Lahdenperä S, Kahri J, Kuusi T, Virtanen KS, Taskinen MR (1995) High density lipoprotein subfractions in noninsulin-dependent diabetes mellitus and coronary artery disease. J Lipid Res 36: 573-582

29. Brinton EA, Eisenberg S, Breslow JL (1994) Human HDL cholesterol levels are determined by apo AI fractional catabolic rate, which correlates inversely with estimates of HDL particle size. Arterioscler Thromb 14: 707-720

30. Horowitz BS, Goldberg IJ, Merab J, Vanni TM, Ramakrishnan R, Ginsberg HN (1993) Increased plasma and renal clearance of an exchangeable pool of apolipoprotein AI in subjects with low levels of high density lipoprotein cholesterol. J Clin Invest 91: 1743-1752

31. Bagdade JD, Lane JT, Subbaiah PV, Otto ME, Ritter MC (1993) Accelerated cholesteryl ester transfer in noninsulin-dependent diabetes mellitus. Atherosclerosis 104: 69-77

32. Kahri J, Syvänne M, Taskinen MR (1994) Plasma cholesterol ester transfer protein activity in noninsulin-dependent diabetic patients with and without coronary artery disease. Metabolism 43: 14981502 